\title{
TLR9 Agonist DUK-CPG-001
}

National Cancer Institute

\section{Source}

National Cancer Institute. TLR9 Agonist DUK-CPG-001. NCI Thesaurus. Code C115959.

A synthetic CpG-rich oligonucleotide with potential immunopotentiating activity. TLR9 agonist DUK-CPG-001 binds to and activates intracellular toll-like receptor 9 (TLR9) in monocytes/macrophages, plasmacytoid dendritic cells (DCs), natural killer (NK) cells and B-cells. This initiates immune signaling pathways, activates DCs, NK cells and B-cells, and induces both the production of T-helper 1 cells (Th1) and a Th1-mediated immune response. TLR9 is a member of the TLR family, which plays a key role in both pathogen recognition and the activation of innate immunity. 